when you come to painful swellings, such as a boil, put on a little heat and it feels better. There is no question abont that; but let us know what we are doing. The moisture used allows stretehing of the dry skin. Therefore, lie believes in a little moisture. There is a point about heat that is worth dwelling on. It does not do any good to the inflammation or to the septic process, but it stops tingling and aching of the nerves. Therefore, Dr. Weir is willing to adhere to a little moisture, hot moisture, on a painful swelling. Otherwise let it alone.

Dr. Artiur Denn Bevan, Chicago, said that in an infected wound of the hand, he believes that the best dressing is the continuous moist antiseptic dressing, very mildly so, either boric acid or acetate of aluminum in a very weak solution; and he believes that it is scientific. The bacteria are rendered less noxious; their growth is inhibited in the dressing, and the drainage is better. The wound secretion flows into the moist dressing, and it is picked up better by it than by the dry dressing, which is hard and uncomfortable. The wet dressing certainly is more comfortable to the patient, and on that account, he is very much in favor of the moist antiseptic dressing in painful swellings.

Dr. Bevan is coming to the use of ointments a good deal. He likes zinc oxid best where the dry, inflexible gauze dressing is uncomfortable to the patient. The old-fashioned flaxseed poultice may be of much value. Why can not such a poultice, when made antiseptic by boiling, be a good dressing and carry no danger to the patient, especially if it gives comfort?

Dr. JABEZ N. JACKson, Kansas City, Mo., said that the action of heat had been discussed simply from the standpoint of hyperemia, the stimulating action of heat on the capillaries. As a matter of fact, he is firmly convinced that the effect of moist heat does not in any sense depend on its effect on the vascular system. Heat has a distinctive effect on the lymphatic system. What happens from the application of heat, either dry or moist, to the skin surface? Your hand is scalded with hot water, and a blister forms. The lymph has been drawn from its usual channels and carried into the skin, showing that the heat has a distinct effect on the lymph circulation. The effect of heat does not depend altogether on the degree of temperature, but on the length of exposure to a uniform temperature. If moist heat is kept up continuously for a time, it has the same effect as has a high temperature for a short time. The effect of heat is to produce outward drainage of the lymphatics; to stop the proximal flow of lymph. The effect of heat is on the lymphatics and not on the blood vessels.

Any agency which can stop the lymph circulation will localize infection. It does not matter what agent or material is used so long as you get the effect of the heat, get a lymph stasis, which will arrest the spread of the infection. In the case of the spreading infections, we add to the moist heat simple incisions and control the infection very rapidly. The application of moist heat in an ordinary contused wound is illogical because it causes lymph stasis and localizes the infection, whereas, if lymph flow is promoted, infection is prevented.

Dr. Criarles Parker, Chicago, commended the wet dressing. Pus in a poultice is better than pus in a wound. The wet dressing should consist simply of ordinary sterile gauze wet with sterile water or salt solution. He did not believe in the necessity of antiseptics. On top of that is placed some impervious tissue. The wet dressing has several functions. One is the absorbing function. It does absorb and clean the wound. An ounce of good absorbent gauze will absorb four ounces of water. When it is moistened, it will weigh about two ounces. It absorbs possibly better than the dry gauze. Dry gauze with plenty of pus will absorb rapidly, but a small quantity of pus will dry in the gauze and from that time on there is no more absorption.

The wet dressing acts as a mechanical diluter of the pus. Change it often. Our final reliance must be on the cells of the tissue. Save as many of these cells as you can. A dry or open dressing allows desiccation of living cells. Now, there are bacteria in the tissues, on the surface and in the dressings. Those in the dressing we do not care about. IVe can throw them away. Those on the surfare are diluted, and a certain number of them go into the dressing. Those in the tissue, none of your antiseptics can reach because the antiseptics will kill the cells if used strong enough to kill germs. Phagocytosis will solve the problem for you. Alcohol and antisepties of all kinds decrease phagocytosis. Save your antiseptics. Induce the lymph to flow into the wounds. Have some means of drainage. Above all, preserve, all the cells you can. Keep them warm. Put on a wet dressing, hot or cold; it will soon be at the temperature of the body.

DR. J. E. Moore said he is simply pleading for the discarding of useless applications and the use of those whose value has been proved. He uses them every day because they make his patients feel better; but they do not cure anything. We must have the extremist. Every time a man speaks of something new he is called an extremist, but in time we reach the happy medium, and then the extremist shall not have been in vain. He does not disapprove of bandages. He has seen swellings disappear many times under the use of bandages. His paper was a plea for surgery without meddling. Meddling is always bad. He has not irrigated a healthy wound for ten years, and he is proud of it.

Moist and dry dressings have their place, but we have no time to work this out to-day. Dr. Weir wants heat and moisture on his boil. So. does Dr. Moore, but it will not cure the boil. Dr. Connelly believes in putting on things to keep the patient busy, and Dr. Moore declared that there is our danger point, because we have not the right to keep our patient busy. Such things bring the profession into disrepute and give the Eddyite a chance to get in his work.

\section{THE CALMETTE OCULAR REACTION TO TUBERCULIN.*}

HARRY C. PARKER, M.D.

Associate Professor of Ophthalmology, Indiana University School of Medicine.

INDIANAPOLIS.

Wolff-Eisner ${ }^{1}$ and Calmette, ${ }^{2}$ working independently, were the first to suggest the conjunctival tuberculin reaction as a diagnostic test for tuberculosis. Since their earliest reports in the spring of 1907 the medical journals in this country and abroad have contained the reports of many observers working along the lines suggested by Calmette. Wolff-Eisner at first used a 10 per cent. aqueous solution of tuberculin which produced a marked conjunctivitis in tuberculous patients, while the non-tuberculous did not show any conjunctival reaction. Calmette used but a 1 per cent. aqueous solution prepared by the precipitation of crude tuberculin with 95 per cent. alcohol, the precipitate being collected and dried. He claimed that in this manner the glycerin and beef extract salts were removed, which in themselves might cause a conjunctival irritation.

Most observers have used the solution prepared in the manner described by Calmette, although several observcrs, notably MacLennan ${ }^{3}$ and Webster and Kilpatrick."." have obtained equally good results with a 1 per cent. aqueous solution of "old" tuberculin. MacLennan tested 25 cases with a 1 per cent. aqueous solution of "old" tuberculin of Koch. Of 14 clinically tuberculous patients. 12 reacted positively; 10 of the positive cases had previously reacted to the Calmette solution.

Calmette ${ }^{4}$ described the reaction as follows: "From the third hour onward the eye in which a 1 per cent.

* Read in the Section on Ophthalmologr of the American Medical Association, at the Fifty-ninth Annual Session, held at Chicago, June, 1908.

1. Fert. kltn. Wochschr., 1907, xliv, p. 700.

2. Compt. rendus de l'Acad. des Sc., June 17, 1907.

3. Brit. Med. Jour., Dec. 7, 1907.

4. Presse Méd., June 19, 1907. 
aqueous solution of tuberculin had been applied became reddened, and in the course of several hours showed all the appearances of a more or less pronounced attack of mucopurulent inflammation of the conjunctiva. The maximum was seen within six or seven hours after the instillation of the tuberculin. All traces of inflammation had disappeared in two or three days. The plan is free from danger and causes the patient scarcely any discomfort."

Various observers recommend solutions of different strengths. Schenck and Seiffert, ${ }^{\circ}$ who make their dilutions with a 3 per cent. solution of boric acid, recommend three different strengths. If the 1 per cent. solution of tuberculin produces no reaction, a 2 per cent. solution is tried, and if this fails a 4 per cent. solution is used.

Comby $^{\circ}$ uses a 0.5 per cent. solution in children, which, he says, is sufficiently strong to produce the reaction and is not harmful. In 132 unselected hospital cases he obtained 62 positive reactions. Ten of the tested cases later came to autopsy, 4 of these had reacted and 6 had manifested no reaction. The postmortem findings confirmed the value of the tuberculin reaction.

Baldwin ${ }^{7}$ recommends 0.33 and 0.5 per cent. as the strength of the solution to be used at first. If these fail a stronger solution is used in the other eye. In a personal letter Dr. Baldwin informed me that he avoids the stronger initial dose and also aroids using the same eye twice, because of a possible severe inflammation. These sequelæ will be considered below.

From the study of nearly 2,200 tested cases taken from the medical literature of the past year it is safe to assert that in the ocular tuberculin reaction we have a test which is equal, if not superior, to any other one test; its application is extremely simple; it almost never produces any constitutional disturbances, and, if the initial dose at least is under 1 per cent. strength, little or no danger can possibly come from its use. A positive reaction almost invariably means tuberculosis, even though the case clinically has not been so diagnosed. The clinician can not always exclude a latent or old tuberculous focus. More postmortem reports on tested cases, both positive and negative, will be awaited with interest.

$\mathrm{Cohn}^{8}$ obtained 8 positive reactions in 12 cases of typhoid tested with tuberculin. He explains these findings by the fact that typhoid cases have a special hypersensibility to bacterial albumin in general as well as to typhoid bacillus extracts. He concludes, however, from a study of 310 cases other than typhoid, that a positive reaction to the ocular tuberculin test is presumptive evicience of tuberculosis. He obtained 38 positive reactions out of 41 cases in the first and second stages of tuberculosis, and only 22 positive reactions out of 45 cases in the third stage of tuberculosis. His observations in this respect agree with many others.

Many observers have obtained positive reactions in all elinically tuberculous cases, while others, like Cohn, have often failed to obtain the reaction in advanced cases. This is explained by the fact that the opsonic index of these patients is low and they offer no resistance to the tuberculin. In this connection it is interesting to note the observations of Smithies and Walker, ${ }^{9}$ one of whom obtained a reaction in his own eye after he

5. Muench. med. Wochschr., 1907, liv, p. 2269.

6. Presse Méd., Aug. 10, 1907.

7. THE Journal A. M. A., Dec. 14, 1907.

8. Berl. klin. Wochschr., Nov. $25,1907$.

9 . ThE Journal A. M. A., Jan. 25, 1908 had been subjected to a subcutaneous injection of $1 \mathrm{mg}$. of tuberculin. The ocular test in this instance was negative previous to the injection of tuberculin. These observers also agrce with the majority, that cases of acute miliary tuberculosis and advanced and moribund cases in which therc is no doubt of the condition often react negatively.

\section{COMPARATIVE DIAGNOSTIC VALUE OF THE SUBCUTANEOUS} INJECTION, VACCINATION AND OCULAR REACTIONS TO TUBERCULIN.

Baldwin ${ }^{7}$ has stated that, while it is too early to compare the value of the ocular and subcutaneous tests, a close similarity in the results have been obtained. Cohn ${ }^{8}$ compared the ocular reaction with Koch's method of subcutaneous injections in a series of doubtful cases which resulted in favor of the ocular test. Mainini ${ }^{10}$ applied the cutaneous test of von Pirquet ${ }^{11}$ in 208 cases and the Calmette reaction in 100 cases. He was impressed with the constancy of the reaction in patients with certain tuberculosis, except those in the advanced stage. He found the cutaneous reaction six times more frequently among patients merely suspected of having tuberculosis than the ocular reaction. von Pirquet, ${ }^{11}$ in 360 tests with the cutaneous reaction in children, found a marked difference between the hyperemia produced in tuberculous and non-tuberculous children under 2 years of age. In older tuberculous individuals the reaction was slight.

Comby ${ }^{12}$ found the age of the child materially influenced the ocular reaction. Under 1 year of age no reaction was obtained, either in tuberculous or nontuberculous infants; in the second year the reaction was very uncertain; beyond 2 years of age the results were similar to those obtained in adults. It is interesting to note that von Pirquet found the cutaneous reaction uncertain in children over 2 years of age, and Comby found the ocular reaction uncertain in children under 2 years.

Warfield ${ }^{13}$ reports 169 cases tested by vaccination, and his conclusions agree with those of Mainini in that the cutaneous test is harmless and is of value in the pretuberculous stage.

Lenhartz $z^{14}$ tried both the cutaneous and ocular reactions in 111 cases, 37 of which were undoubtedly tuberculous. Of the 37 tuberculous patients, 15 had been previously treated with subcutaneous injection of tuberculin. Of these the cutaneous test was negative in 6 , well marked in 4 , distinct in 2 , and doubtful in 3 . The ncular test was positive in 11 , doubtful in 2 , and not tried in 2 . The better results in these cases with the ocular test may have been due to the previous injection of tuberculin, as Smithies and Walker ${ }^{9}$ obtained an ocular reaction in a non-tuberculous patient after tuberculin had been injected subcutaneously. In 11 of Lenhartz's cases, clinically non-tuberculous, the ocular and cutaneous reactions gave about the same results. Of 63 suspicious cases, 23 were positive to both, 40 negative to the cutaneous, and 36 negative to the ocular test (this test being omitted in 4 ).

\section{IS THE OCULAR TUBERCULIN TEST HARMLESS?}

Calmeti $\mathrm{e}^{15}$ has recently claimed that in more than 10,000 cases already tested its harmlessness has been

10. Muench. med. Wochschr., Dec. 24, 1907.

11. Berl. klin. Wochschr., May $20,1907$.

12. Rev. Méd. de la Suisse Romande, 1907, xxvil, p. 888.

13. The Journal A. M. A., Feb. 29, 1908 .

14. Muench. med. Wochschr., Nov. 26, 1907.

15. Bull. de l'Acad. de méd., Jan. 14, 1908. 
proven. Delorme, in his discussion of Calmette's paper, cited 39 cases of excessive conjunctival reaction.

De Lapersonne, ${ }^{16}$ in his investigation of alleged injury to the eye from the instillation of tuberculin, found six cases of ulcero-vascular keratitis, which were, with one exception, in patients having a pre-existing lesion of the cornea. All recovered with good vision. He found in two other cases intraocular sequelæ which took the form of iridocyclitis. De Lapersonne advises against the use of the ocular test until both eyes have been thoroughly. examined. He also advises against using this test in differentiation of lesions of the eyeball, whether deep or superficial, although it might be used in the diagnosis of diseases of the lids, orbit and lachrymal organs. The complications noted by De Lapersonne did not become manifest until from ten to twenty days after the instillation.

Netter $^{17}$ has recently protested against too much enthusiasm for the ocular reaction, because of its liability to be followed by serious consequences. He said that he knew of several instances in which Parisian ophthalmologists had been treating severe eye trouble following the instillation of tuberculin.

Eisen $^{18}$ reports two serious conjunctival reactions in 45 tests. Both patients had suffered from conjunctivitis in youth. The reaction in these patients was so severe that they were turned over to an ophthalmologist for treatment.

Feer's ${ }^{19}$ experience with both the ocular and cutaneous tests leads him to warn against the use of the ocular test in serofulous children, for the reason that it is liable to incite a severe and lasting conjunctivitis.

Weins and Gunther ${ }^{20}$ report several instances of serious trouble in their experience. In one case, a child of 3 had a severe chronic conjunctivitis following the instillation of the tuberculin which was still evident after many months. In another case the instillation was followed by swelling and suppuration of the conjunctiva, and this, in turn, was followed by the formation of phlyctenular ulcerations which were present for over three months. In another case the reaction soon subsided, but it was followed by conjunctival hemorrhage and inflammation, the latter lasting over a week. In 38 cases tested with 0.5 per cent. solution the reaction was negative in all but one. In this case a pre-existing mild conjunctivitis became much aggravated, with membrane formation, hemorrhages. keratitis, and severe subjective disturbances. The end-result, however, in this case was complete recovery.

H. Truc ${ }^{21}$ declares the ocular test to be entirely harmless even when applied to individuals with ocular lesions. The reaction occurred with equal intensity in the diseased as in the sound eye, and, so far as be could judge, had no bad effect on the diseased eye.

Baldwin ${ }^{7}$ gives acute or chronic conjunctivitis, blepharitis, keratitis, trachoma, or any disease of the cornea and internal structures of the eye as contraindication to the use of the ocular tuberculin test. In a personal letter Dr. Baldwin cites the case of a colleague on whom the reaction was tried: "The instillation was followed by edema of both eyelids and great swelling of the bulbar and palpebral conjunctivæ. In over 200 individuals there have been at least five severe reactions, ranging

16. Presse méd., Dec. $7,1907$.

17. Soc d'Ophth. Paris, 1907.

17. Soc. dophth., Paris, 1907.

18. Pelt. z. Klin. d. Tuberk., vii, No. 4.

19. Muench. med. Wochs
20. Ibid., Dec. 24, 1907.

21. Soc. d'Ophth., 1907 from deep injection and tumefaction of the entire conjunctiva and edema of the lids to ecchymoses, which have occurred in two instanc's."

Dr. Frank Smithies, of Ann Arbor, in a personal letter, stated that a more intense reaction was obtained in patients having a pre-existing conjunctivitis. One patient under his observation, a syphilitic with an old arthritis, reacted so strongly to a second instillation that the inflammation was cleared up with difficulty. This patient at the time was taking iodids.

Webster and Kilpatrick ${ }^{22}$ mentioned one case of phlyctenular conjunctivitis following recovery for the ocular reaction. 'They reported 121 cases tested with the 1 to 100 "old" tuberculin solution.

\section{THE OCULAR REACTION IN OPHTHALMOLOGY.}

Stephenson ${ }^{23}$ was one of the first ophthalmologists to apply this test for the differential diagnosis of ocular lesions. He says in his report: "The preponderating part unquestionably played by syphilis in the production of many ocular affections has, perhaps, tended to render some of us a little blind to the influence of other causes, prominent among which, as I believe, stands tuberculosis. How often do we meet disseminated chorioiditis indistinguishable by ophthalmologists from the form due to syphilis in patients in whom there is no evidence whatsoever of a specific taint, acquired or inherited? I feel confident that no small number of such non-syphilitic cases are in reality due to tuberculosis."

Stephenson's cases are:

1. Phlyctenular Keratitis and Conjunctivitis.--Six cases of long standing in children. Only two of these cases manifested other tuberculous lesions. All gave positive reaction; one recent case of phlyctenular keratitis gave a negative reaction.

2. Chorioiditis.--Three cases in young women without syphilitic taint, and presenting no other tubercular lesions. All three tests positive.

3. Interstitial Keratitis.-Eight cases tested; five showed typical signs of inherited syphilis. These five cases gave no reaction; the other three cases gave positive reactions.

4. Episcleritis.--Three cases tested; one positive case, which showed enlarged glands, the other two cases negative.

5. Tubercle of Iris.- One case in a girl of 12 , who had had severe inflammation of left eye for six months. Anterior chamber filled with dense exudate. No general clinical signs of tuberculosis or syphilis. Case gave positive reaction.

6. Tubercle of Cornea.-One case in girl of 12 . Cornea showed patchy deposits, rest of cornea hazy. Posterior synechix. Ophthalmoscope revealed areas of yellowish-white exudate in cornea. Reaction positive.

7. Chronic Iridocyclitis.-Two cases, both positive; one case was in a child of 9 , the other in a woman of 34 .

Painblau ${ }^{24}$ reported two cases of tuberculosis of the conjunctiva which reacted positively. Brunetière ${ }^{24}$ reported three negative reactions in cases thought possibly to be tuberculous, keratoiritis, interstitial keratitis, and exudative chorioiditis. Later Brunetière affirmed the diagnostic value of the ocular tuberculin reaction as a means of differentiating ocular lesions.

Aubaret and Lafon ${ }^{25}$ report the use of the ocular reaction in 18 ophthalmic cases with positive reactions. These cases included intraocular tuberculosis, phlyctenular keratitis, episcleritis, interstitial keratitis, lachrymal affections and optic neuritis.

H. True ${ }^{21}$ tested 23 patients with various ocular lesions, 4 having certain or suspected tuberculosis gave a positive reaction, 4 other reactions were positive in

22. Brit. Med. Jour. Dec. 7, 1907.

23. Brit. Med. Jour. Oct. 19, 1907 .

23. Brit. Med. Jour., Oct. 19, 1907.

¿5. Gazette Hebd. des sciences méd. de Bordeaux, Aug. 4, 1907. 
patients showing no clinical signs of tuberculosis. The other 15 cases gave no reaction.

Dr. George Derby, of Boston, was kind enough to send me the results of his experience with the Calmette reaction up to Jan. 21, 1908. He had tested 24 cases, 8 of which were controls. Two of the controls gave a positive reaction, one having a tuberculous family history, and the other could not be followed up. Of the 16 remaining cases, 15 had ocular lesions which might have been tuberculous. Among the cases manifesting ocular lesions there were 5 cases of phlyctenular keratitis, one of which gave a positive reaction, later confirmed by subcutaneous injection, and one gave a doubtful reaction. The remaining 3 cases were negative. Two cases of recurrent sclerokeratitis were positive. Three cases of interstitial keratitis giving specific history were negative. Three cases of scleritis gave one positive reaction, later confirmed by subcutaneous injection. One case having corneal ulcer and another with chorioretinitis were negative.

Derby advises against the instillation of the tuberculin in a diseased eye. He mentioned one case in which the tuberculin had been instilled into an apparently normal eye to find on more careful cxamination an old corneal scar. The reaction in this case was followed by a mild episcleritis which lasted several weeks.

My own experience with the test has been so limited that a summary of my cases seems hardly worth while. Dr. John IR. Thrasher obtained the cases of certain or suspected tuberculosis for his clinic in the Indiana University School of Medicine; he also made the sputum examinations and aided me in following up the cases. I made 31 tests, 7 of which were second tests in cases in which the first reaction was negative. The Calmette solution, 1 per cent., was made from tablets furnished me by the experimental department of Parke, Davis \& Co. In the 24 cases tested, 3 were positive and 1 doubtful. One positive reaction was obtained in a colored woman having a subacute bronchitis and enlarged cervical glands; sputum negative. The doubtful reaction was obtained in a case of lung tuberculosis; sputum positive. Three cases of advanced tuberculosis showing numerous bacilli in the sputum gave a positive reaction in one case; the other 2 cases gave negative reactions. Of the 24 patients, 5 had ocular lesions, but were in other respects apparently normal. One case of optic atrophy was negative; one case of hyalitis with deposits on Descemet's membrane was negative; a case of phlyctenular keratitis in one eye gave a positive reaction when the solution was instilled into the sound eye; one case of interstitial keratitis, undoubtedly specific, was negative, and one case of central chorioretinitis was negative.

FREQUENCY OF TUBERCULOSIS OF THE EYE.

Helbron ${ }^{26}$ claims that 0.5 per cent. of 15,000 ophthalmic affections in the Berlin eye clinic were due to tuberculosis. Stock's ${ }^{2 \tau}$ report of 59 cases of chronic iridocyclitis, of which 61 per cent. reacted to the subcutaneous injection of Koch's "old" tuberculin, shows the great number of this class of cases caused by tuberculosis. Verhoeff ${ }^{28}$ and Bull ${ }^{29}$ have within the past year called our attention to the tuberculous nature of many cases of scleritis and episcleritis. These tuberculous

26. Muench. med. Wochschr., Jan. T. 1908

27. Tuberculose als aetiologie der chronischen Entzündungen des Auges und seiner adnexæ besonder's der chronischen Uveitis, Ieipzig, 1907 .

‥ Ioston Med. and Surg. Jour., March 14, 1907

29. Tile JuUnnal A. M. A., Aug. 3, 1907. cases have reacted to the subcutaneous injection of both the "old" tuberculin of Koch and the tuberculin T.R. Prof. Carl Hess, $: 9$ in the discussion of Bull's paper, said that he used tuberculin for diagnosis in akout 100 cases and over 50 per cent. of these cases had given a general reaction. Törok ${ }^{30}$ reports 16 cases of tuberculosis of the eye treated with tuberculin injections. These cases included tuberculosis of the conjunctiva, sciera, iris and chorioid.

Chance, ${ }^{31}$ in a paper on iritis in general disease. makes the assertion that tuberculous iritis is much more common than it was formerly supposed to be.

Brücker $^{32}$ cites 38 eye cases in which tuberculin was injected for diagnostic purposes. Of 12 acute cases of iritis only 2 reacted, while in 14 cases of chronic iritis or iridocyclitis 11 reacted.

\section{CONCLUSIONS.}

1. The Calmette ocular tuberculin test is of as great diagnostic importance as any other single test.

2. A positive reaction is indicative of a tuberculous focus somewhere in the body.

3 . The test is uncertain in patients under 2 years of age, in whom the cutaneous test of von Pirquet is most certain.

4. The test fails in advanced cases of tuberculosis but there is little need of it here for diagnostic purposes.

5 . The initial instillation should be preferably under 1 per cent. strength, in order that severe inflammatory conditions may not follow its use.

6. If necessary to make the second and stronger test the instillation should be made in the eye not previously used.

\%. The consensus of opinion seems to be against using the test in an eye not wholly normal.

8. After-complications have occurred from the use of the test, but these have entirely cleared up in a varying length of time. These conditions are not so frequent when the initial test is made with a solution under 1 per cent. in strength.

9. Recent investigations have shown a greater number of ophthalmic affections due to tuberculosis than formerly supposed, and in the Calmette reaction we have a simple means of differential diagnosis which should be thoroughly tried.

10. The ocular reaction is especially valuable for ascertaining the tuberculous nature of cases of phlyctenular keratitis and conjunctivitis, episcleritis and scleritis, chronic iritis and iridocyclitis, interstitial keratitis, and chorioiditis.

11. A 1 per cent. solution of Koch's "old" tuberculin is nearly as good as the Calmette solution for diagnostic purposes.

12. The test in the hands of various observers has given such uniformly excellent results that its value is practically assured.

\section{DISCUSSION}

ON PAPERS OF DRS. IEWIS* AND PARKER.

Dr. Lreweliyn Williamsox. St. Jonis, said that all had seen cases of gastric neuroses dependent on some error of the visual apparatus. Occasionally, he said, some reference to these neuroses was found in the writings of ophthalmologists; but no one, heretofore, had called attention to the very important factor these gastric neuroses of ocular origin might play in the etiology and treatment of tuberculosis.

30. Arch. Ophth., September. 1907.

31. Therap. Gaz, August, 1907.

32. Arch. Ophth.. September, 1907, xxxvi, 647.

* The paper of Dr. Lewis was mblished June 13. 
Dr. Williamson said that earnest efforts must be put forth before general practitioners as a class will recognize that ocular neuroses were not confined to headaches alone. He believed that the diagnosis of many obscure conditions could be distinctly aided by ophthalmologists and that a closer com. munion and interdependence between the ophthalmologist and the internist was becoming every day more desirable.

Derangements of the visual system and tuberculosis of the lungs might seem to have no connection, and yet, a little thought will show that they might be closely related. Dr. Williamson said that the opportunities for tuberculous infection were enormous and the number of autopsies in which tlat infection was found where no such trouble had been swepected during life, was much beyond anything suspected by those who had not especially investigated the subject. A colleague of large experience in tuberculosis had recently told Dr. Williamson that he was quite confident that at least 75 per cent of all persons had tuberculosis at some time during their lives. It was evident, Dr. Williamson said, that a great many patients recovered and that the factor which played so important a part in the recovery of these cases, was the vital resistance of the body. Not only did lessened resistance play a large part in the patient's recovery in already existing infection, but also in rendering more easy an initial infection. Anything, then, which diminished the tone of the system, was an important factor in tuberculosis. Dr. Williamson stated that eyestrain might, and frequently did, play an important part in the waste of nerve force, and consequent lowering of bodily tone; so that the connection between the eye and sys. temic tuberculosis did not seem far distant after all.

On the authority of a vast array of modern writers, Dr. Williamson stated that the three grand essentials in the treatment of tuberculosis were fresh air, proper and abundant feeding, and rest, combined with judicious exercise; and that of these, the most important was, undoubtedly, feeding. This had been recognized since the time of Paracelsus, in the sixteenth century.

Could disturbances of the visual apparatus, the speaker asked, have any influence on the digestion? He replied by quoting from Bulson, Ambrose Ranney, and Starr, whose tes timony indicated that a frequent result of eyestrain in its various fields was the disturbance of the digestive apparatus. In a large number of cases, the disappearance of the digestive disturbance was reported as following more or less promptly on the correction of the visual defect, and in many instances, a recurrence of the symptoms had been observed following the disuse of the glasses. It was abundantly demonstrated that very many cases of digestive derangements had their origin solely in error of vision. In further support of these ronclusions, Dr. Williamson cited Professor Muesser, and Cohen's "Physiological Therapeutics." Since then, a healthy condition of the digestive organs was of prime importance in the successful treatment of tuberculosis, and since errors of the visual system might by reflex action, seriously impair the proper performance of the functions by the digestive system. Dr. Williamson believed that the importance of a thorough examination of the eyes in all cases of tuberculosis required no argument. He was thoroughly in accord with Dr. Lewis and thought the subject should be insistently put before the general body of medical men.

DR. E. R. LEwis, Dubuque, Iowa, said that a widely heralded, plausible novelty had appeared in the diagnostic field, but the profession must not let seductive simplicity or dazzling possibilities lure them away from strict observance of the commandment: "Prove all things; hold fast that which is good." Dr. Lewis believed that nothing could be more unfortunate than that the impression should spread abroad among careless unscientific members of the medical profession that these tests furnished a "ready made" diagnosis; that by sending for a bottle of tablets, following directions and observing reactions they would be enabled to give an opinion stamped with the approval of the world's best investigators. He said that the tests of von Pirquet and Calmette offered no short cut to a high plane of scientific attainments; but that on the contrary, their application must be based on a thorough familiarity with the theory of immunity-and the experimental work of Ehr- lich Römer, Martin and Cherry, Courmont, Doyon and the other workers in this until recently virgin field.

Dr. Lewis believed that it was premature to attempt to discuss the comparative diagnostic values of the subcutaneous injection of Koch's old tuberculin, von Pirquet's vaccination test and Calmette's conjunctival test. For purposes of such a comparison, uniformity in the essentials was a sine qua non. He said that of these three tests but one had been applied with anything like this uniformity by the multitude of observers whose reports must go to make up our verdict; that was the test with Koch's old tuberculin.

Dr. Lewis said that he had analyzed reports of 22 observers since appearance of the reports collated by Smithies and Walker. These included 2,080 cases in which the ocular test was applied, the reagent being Calmette's alcoholic precipitate in 750 , old tubereulin in 923 , new tuberculin in 10 , and reagent not specified in 397 .

Ir. Lewis summarized the evidence against the specificity of the reaction in these reports in the following table:

Positive REACTIONS.
10 out of 17
2 out of 5
3 out of 6
3 out of 3
9 out of 235
Several.
Several.

DISEASE PRESENT.

Typhoid. Patients clearly non-tubercular. Scarlatina. Patients clearly non-tubercular. Acute bronchitis. Patlents clearly non-tuberc. Acute-enteritis. Patients clearly non-tuberc. No disease. Patients apparently healthy. Acute gonorrheal arthritis.

Acute gonorrheal arthritis.
Three cases of unquestionable tuberculosis of mild type.

Dr. Lewis said that Mainini based on 308 cases, the opinion that the ocular reaction was very probably not specific; that Kleineberger, from observation of 61 cases believed that a reaction to a second instillation in the same eye expressed merely hypersensitiveness; that Stadelmann, observing a large number of cutaneous reactions, believed that this test had no diagnostic importance; that Webster and Kilpatrick concluded that the ocular reaction gave some promise of utility, but that its reliability could be determined only after much more extended research; and that Downes warned against at taching undue importance to results of the ocular test, either positive or negative.

Dr. Lewis thought that careful analysis of the evidence presented must arouse doubt as to which of the positive reactions supplied evidence of a non-specific response of the tissues to an irritant and which must be considered evidence of receptor combining with toxin.

In construing the negative reactions, Dr. Lewis said that without considering the possibility of faulty technie, two widely varying meanings must be considered: Absence of tuberculosis; or presence of tuberculosis in a body so low in resisting power as to be unable to manifest a reaction indicating specific opposition to the instilled tuberculin.

Dr. Lewis considered the question of possibility of harmful effects from applying the conjunctival test to be of very great importance. He quoted Stadelmann, Serafini, Plehn, and others as having observed a tendency on the part of conjunctivæ subjected to the Calmette test to flare up into more or less violent inflammation long after subsidence of reactionary symptoms.

In his experience, comprising observations made on 71 cases, Dr. Lewis had seen no untoward results following instillations of 0.5 per cent. and 1 per cent. solutions of the alcoholic precipitate. Most of these cases presented positive clinical evidence of the existence of tuberculosis; yet, in less than 50 per cent. was the reaction to the conjunctival test positive. Yet he said some observers reported as high as 97 per cent. positive in cases of clinically positive tuberculosis. He realized a most crying need for the adoption of uniform technic in the application of the von Pirquet and Calmette tests, and felt that as yet the tests of von Pirquet and Calmette had made no enduring place for themselves in the diagnostic system, but he hoped that finally they would fill definite places among methods of precise diagnosis.

Dr. Jorn Green, St. Louis, said that a limited experience with the Calmette test in fourteen cases of suspected tuberculosis had impressed him with two possibilities: Excessive reaction, and the occurrence of reaction when other tuberculosis tests are negative. Illustrating the first possibility, 
he cited a case of recurrent uveitis, in which the fellow eye was blind. A 0.5 per cent. tuberculin instilled into the blind eye had evoked an excessive reaction and despite vigorous treatment, nearly a month had elapsed before the conjunctiva was restored to normal. As illustrative of the second point, Dr. Green referred to a young man with doubtful specific history, who presented a central chorioiditis of several months' duration; 0.5 per cent. tuberculin instilled into the normal eye had evoked, in twelve hours, a typical reaction which subsided promptly. Several days later the cutaneous method gave no reaction. Under increasing doses of the iodids, absorption took place with disappearance of the lesion, which seemed to point to the non-tuberculous nature of the process.

Mr. E. Treacher Collins, London, England, said that it had always seemed strange to him that the profession had been so loath to recognize tuberculosis of ocular origin. Every new test which was brought out for tuberculosis compelled the recognition of the fact that eye disease was more frequently tuberculous than was formerly thought.

He said that he and his colleagues had had a good deal of experience with the Calmette test in London and had found it not altogether devoid of unpleasant symptoms. He had had one case, (a mucopurulent conjunctivitis), in which the reaction lasted quite three weeks after an application of 1 per cent. solution, and two of his colleagues had had cases of chorioiditis follow such applications.

Mr. Collins said that there was one form of intraocular inflammation which could be recognized as tuberculous from its clinical character apart from these tests. This was an episcleral chorioiditis. He explained that the lymph spaces between the ciliary body and the sclera were favorable sites for the starting point of tuberculosis; that the nodule presented itself as an episcleritis; and that the tubercle then continued to spread forward in these lymph spaces and involved the ligamentum pectinatum, then presenting the symptoms of a marginal chorioiditis. Sometimes, he said, the tubercle was arrested at that point, and the condition cleared up. It was the condition often diagnosed as of rheumatic origin and he believed that the majority of these cases were really tuberculous in origin. If the course of the disease progressed unchecked it extended to the ciliary muscle and the ciliary body and a chorioiditis punctata in connection with it, and sometimes a lowering of intraocular tension, was the result. He said that sometimes a nodule formed at the periphery of the chamber, which made the diagnosis of tubercle very certain. The ciliary body might be destroyed, the function of the eve lost, and the condition end in a shrunken globe. Mr. Collins thought that it was a condition that could be recognized from its clinical characteristics alone.

Dr. A. E. Davis, New York, said that he did not believe that the relief of abnormal visual conditions was a necessary prerequisite to recovery from pulmonary disease. He said that, of course, all recognized the fact that anything that lowered the vitality in these cases had a detrimental effect on recovery, but he thought that it would be somewhat misleading to say that glasses gave such relief before further investigation on the subject with the accumulation of data of hundreds or thousands of cases, and by a number of observers. Dr. Davis asked Dr. Lewis to state what percentage of cures in these cases he attributed to the wearing of glasses.

Dr. G. F. KeIPER, Lafayette, Ind., said that he also had written a paper on the Calmette reaction and now found that it needed revision. He said that the test was but a year old and that, because of that fact, it was yet too early to draw any thing in the way of positive conclusions concerning its value. Dr. Keiper stated that all observers had agreed that an eye involved in any process of disease should not have the tuberculin introduced because of the danger of excessive re. action likely to follow. It was his opinion that it would be best to make the subcutaneous, or von Pirquet test, and exclude the instillation of tuberculin in the eye itself. He thought also that it would be wise here to follow parliamentary procedure and refer the matter to proper committees in order that they might bring before the Section the results of such investigations, that they might have something definite to go on It would often save them from some distressing results in trying these new things, and it might guard against possible lawsuits.

DR. EDWARd Jacksor, Denver, said that Mr. Collins' remarks as to involvement of the region immediately beneath the anterior portion of the sclera had been of special interest to him in connection with a case that he now had under treatment. The patient had lost one eye about ten years ago from chronic uveitis and was now suffering from the third attack of uveitis in the second eye. Using the Calmette test in the blind eye, Dr. Jackson obtained a typical reaction that lasted sixteen days, but without anything more than what might be regarded as a rather severe reaction to the test. The patient had been placed on hypodermic use of the tuberculin-an injection once a week; there had been a slight general reaction after several of these injections, and at least three times there had appeared in the limbus three or four striking spots of hyperemia. Dr. Jackson said that he had examined them under magnification and found that they were little spots of increased vascularity right under the edge of the selera.

Dr. Ronert Randolpir, Baltimore, said that they had been in the habit of using this reaction as a routine practice in the Phipps Laboratory of the Jolıns Hopkins Hospital, and had been much impressed with the nicety of the test. But he said that, like the other tests, for example, von Pirquet's, it was apt to mislead by revealing a condition which was clinically of no importance; in other words, a positive reaction not in. frequently meant a long-healed focus or foci in an individual who was practically sound. He considered a negative reaction of more value, as indicating that the individual was probably sound. Dr. Jackson said that this test was occasionally reported as reacting positively in normal individuals, but some recent investigations, conducted in Escherich's clinic, showed that this was not so. A number of individuals in whom the Calmette test was negative, who clinically were free of tuberculosis, and who died of other diseases, were shown to be entirely free of tuberculous foci when they came to autopsy.

Dr. Nelson M. BLACK, Milwaukee, said that in none of the cases reported of severe conjunctivitis following the use of the ophthalmic reaction had the condition of the conjunctiva previous to the application of the test been stated. He asked if it was not possible that a bacteriologic cxamination of the contents of the conjunctival sac before applying the test would be wise. He thought that some of the apparently non-pathogenic bacteria frequently found in the secretion of the eve might become pathogenic or that the condition brought about in the sac by the action of the tuberculin might produce a culture medium, permitting the bacteria found in the eye to become active and produce a purulent inflammation.

Dr. A. R. BAKER, Cleveland, said that he had not felt called on to use this ocular tuberculin test. He did not think that he knew enough about it; but he had found that the young physicians in the dispensary were using it and he had seen some bad reactions.

Dr. Hiram Woons, Baltimore, said that in the Children's Hospital, in Baltimore, he had followed a series of 37 cases in which the test had been used. In one child, a 0.5 per cent. solution used in one eye failed; the child had had, at the time, a small stye on the lid of the other eye. Four weeks later $l$ per cent., used in that eye, was followed by a mucopurulent conjunctivitis; a small bleb appeared at the limbus which developed into one of the most obstinate corneal ulcers that Dr. Woods had ever seen. That was the only bad result. Dr. Woods said that those who had had most experience with the test warned that it should not be used in an inflamed eye. In view of what Mr. Collins had said of the extreme anterior point at which the tuberculous process might begin. Dr. Woods thought it necessary to be very careful lest an infection exist at a place where it might be overlooked.

Dr. F. Park Lewis, Buffalo, said that he had no desire to generalize on matters about which particulars were essential. He thought that perhaps the summary of his paper would lead to the belief that he considered all cases of tuberculosis as having an ocular basis; of course, he believed nothing of the kind. Dr. Lewis said that a large number of cases of refractive error might have no manifestations, but if it were possible that a certain number of cases did, the eye 
should be investigated in the suspected tuberculosis patients. He added that his purpose was not necessarily to have action taken by this Section, but to emphasize that such an ocular basis for tuberculosis existed and that whenever it did, it was necessary to investigate the matter and consider closely the relation of the eye to the general condition, that this rela. tion might not be overlooked.

Dr. H. C. PARKer, Indianapolis, said that he had not made over ten tests within the past two months, and in only one of these had he obtained a positive reaction. This reaction had been obtained in a nurse used as a control in whom there was not the slightest evidence of a tuberculous condition either present or past, and whose family history was excellent. In this case the reaction was violent with marked subjective symptoms, accompanied with purulent discharge, the lid showing edema and chemosis. A smear taken from the conjunctival sac showed numerous lance-shaped diplococci resembling closely and ealled pneumococci. Several of Dr. Parker's later negative tests were made in undoubted cases of clinical tuberculosis.

Dr. Parker said that several recent writers had become enthusiastic over the results obtained by the Calmette reaction, while others had put forth a warning note either against its reliability or its too promiseuous use by physicians possessing no intimate knowledge of ocular lesions, past or present.

Arnold Knapp's case (reported in the Archives of Ophthalmology, March, 1908) of interstitial keratitis following the instillation of Calmette solution in an eye previously healthy showed that the test was not without danger.

Weber, in the British Medical Journal, Feb. 15, 1908, reported the cases of five healthy doctors who tried the test on themselves, each obtaining a positive reaction, three of which were violent.

Dr. Parker said that it was without doubt true that much more information was necessary on this subject; also that the test should be made only in eyes showing no ocular lesion or sear on the surface of the eyeball; and that, even in such instances, the test was not free from some danger.

\section{COLLES' FRACTURE: WTTH A NEW THEORY OF ITS MECHANISM.*}

\author{
LEONARD W. ELY, M.D. \\ Consulting Orthopedist to the Roosevelt Hospital. \\ NEW YORK.
}

For the past two or three years an effort has been made to evolve a simple, practical method of treating this fracture, that may be relied on to give good results in the hands of the general practitioner. The subject has been so interwoven with all sorts of queer theories as to causation, symptoms and treatment, that the truth is hard to pick out. The great fault seems to be that those who have successfully treated the injury themselves have failed to emphasize the essential points of the treatment. The problem was to lay down an exact form of procedure that will enable one who seldom sees the fracture to recognize it without the aid of an $x$-ray apparatus when it appears, and to treat it successfully.

'The conclusions set forth in this paper are based on experiments on the cadaver, and also on the study of about fifty cases, the greater number of which were seen at the Roosevelt Hospital Out-Patient Department, though some were observed in other clinics and private practice. Since perfecting the method we at the Roosevelt Hospital Dispensary have never had a bad result. Some of the results can be classified only as fair, but many are almost perfect, and in some cases the injured wrist can hardly be distinguished from the sound one. We regard this fracture, not as one of the most difficult

* Read at the annual meeting of the Monroe County (N. Y.) Medical Society, May 19,1908 . and unsatisfactory to treat, but as one of the simplest and most gratifying.

Now, in the first place, let it be understood what is meant by a Colles' fracture. It is a fracture of the radius in its lowest inch, usually in the lowest threequarters of an inch. It is this and nothing more. Often, comminution is present; usually the lower fragment is displaced, and almost invariably there is enough interlocking of the fragments (impaction) to hold them together in their new position (Figs. 4. 5 and 6). In this impaction the posterior part of the bone usually suffers more than the anterior, and the external part more than the internal. Hence the tilting back of the lower fragment (silver fork deformity), and the abduction of the hand. Frequently the styloid process of the ulna is fractured, and the triangular fibrocartilage is dislocated at the same time (Figs. 6 and 8). All this is interesting and more or less instructive, but the essential point for us to remember is that a Colles' fracture is an impacted fracture of the lower three-quarters of an inch of the radius.

The cause of the fracture is almost invariably a fall on the heel of the extended hand. This is the one point about the injury that is well understood. The position of the hand has nothing essential to do with the fracture, except that extension is the only position the hand can be in to transmit the blow to the radius when one falls on one's hand.

Many theories have been advanced as to the mechanism and as to the production of the usual deformity, but none of them has been generally accepted. I have learned more from a few simple experiments on the cadaver than from the observation of many clinical cases. A cat thrown out of the window lands on all fours and fractures no bones. A man falling on both hands rarely fractures a wrist. Hence the rarity of double Colles' fracture. It is extremely difficult to fracture the radius of a cadaver by blows on the superextended wrist. I succeeded in breaking the lower end into several pieces, but did not cause impaction. What are the reasons for this phenomenon?

1. Why does a fall on the hand so frequently break the radius at this spot? Because this is the weakest point between the wrist and the shoulder. The structure of the radius here is cancellous and is not arranged to withstand a force applied longitudinally. The thicker layer of dense bone just above resists the strain and is driven down into the lower fragment. At a short distance above the wrist begins the interosseous membrane, which, running downward from the radius to the ulna, transfers the strain to the latter bone, and thus relieves the upper end of the radius (Fig. 1).

2. Why does the outer part of the bone suffer more than the inner? Because the inner portion is held fast to the ulna, while the outer portion is free (Figs. 1 and 4), and hence swings up and meets more of the force of the blow. Not until the styloid process of the ulna is broken and the triangular fibrocartilage is dislocated is the internal portion of the bone exposed to impaction (Fig. 6). Again, the fall is usually on the radial side of the hand.

3. Why does the posterior or dorsal aspect of the bone usually suffer more than the anterior (Fig. 7). This has been a stumbling-block heretofore of all investigators. In point of fact the explanation is perfectly simple. A section at the usual seat of fracture shows the bone here 